\title{
Característica leucocitária, relação albumina/globulina, proteína plasmática e fibrinogênio de bovinos da raça Nelore, confinados e terminados a pasto
}

\author{
Leukocyte characteristic, albumin/globulin relation, plasmatic protein and fibrinogen of bovines \\ of the Nelore race confined and grazing
}

\author{
Ediane Batista da Silva ${ }^{I^{*}}$ Maria Clorinda Soares Fioravanti' ${ }^{\mathbf{I}}$ Luiz Antônio Franco da Silva ${ }^{\mathrm{I}}$ \\ Eugênio Gonçalves de Araújo ${ }^{\mathrm{I}}$ Liliana Borges de Menezes ${ }^{\mathrm{II}}$ Marina Pacheco Miguel ${ }^{\mathrm{I}}$ \\ Dirson Vieira ${ }^{\mathrm{I}}$
}

\section{RESUMO}

Esse trabalho avaliou as mudanças na contagem de leucócitos e algumas proteínas séricas de bovinos confinados e terminados a pasto. De 120 amostras sangüíneas coletadas, 60 foram obtidas de bovinos Nelores machos confinados e 60 de animais com as mesmas características, porém manejados extensivamente. As amostras foram obtidas por ocasião do abate desses animais. Os parâmetros estudados foram contagem de leucócitos, razão albumina/globulina e concentração de fibrinogênio plasmático. $\mathrm{Na}$ análise dos dados empregou-se estatística descritiva, obtendo-se as médias, desvio padrão e coeficiente de variação para todos as variáveis avaliadas e posteriormente comparou-se as médias por meio de teste nãoparamétrico. Os bovinos terminados a pasto apresentaram maior nível de globulina e fibrinogênio $(P>0,05)$ quando comparados com os confinados (globulina: pastejo $=3,29 \mathrm{~g}$ $d L^{-1} 0,76$; confinamento $2,99 \mathrm{~g} d L^{-1} \pm 0,60$ e Fibrinogênio: pastejo $=872 \mathrm{mg} \mathrm{dL}^{-1} \pm 610$; confinamento $=633 \mathrm{mg} \mathrm{dL}^{-1} \pm 319$ ). O número de leucócitos total foi de 7,64 2 2,15 em bovinos confinados e de 7,72 $\pm 1,84$ nos terminados a pasto. Não houve diferença $(P>0,05)$ entre essa variável e a contagem diferencial de leucócitos bem como na proteína sérica total $\left(g d L^{-1}\right)$ dos bovinos terminados a pasto $(6,10 \pm 0,53)$ e dos confinados $(5,96 \pm 0,49)$. O nível de albumina dos bovinos confinados $\left(3,01 \mathrm{~g} d L^{-1} \pm 0,43\right)$ e a razão $A / G(1,07 \pm 8,91)$ foram maiores quando comparados com os bovinos terminados a pasto $(2,82 \mathrm{~g}$ $\left.d L^{-1} \pm 0,45\right)$ e $(0,95 \pm 0,38)$ respectivamente. O nível mais elevado de albumina nos bovinos confinados sugere que eles foram submetidos a uma dieta nutricional mais adequada. O constante desafio imunológico sofrido pelos animais terminados a pasto pode ter sido responsável pelo elevado nível de globulina e fibrinogênio. Esses resultados indicaram que, apesar das adversidades que os bovinos confinados são submetidos, eles não apresentaram alterações correlacionadas com esse fato.

Palavras-chave: criação extensiva, bovinos, leucócitos, proteínas plasmáticas.

\section{ABSTRACT}

This research aimed to evaluate the changes in the white blood cell count and some serum proteins of confined cattle (CC) and grass cattle (GC). From the 120 blood samples collected, 60 were obtained from confined Nelore male bovines and 60 from animals with the same characteristics but managed extensively. Samples were obtained at the moment of slaughter. Parameters studied were the white blood cell count, serum albumin/globulin ratio and concentration of plasma fibrinogen. Descriptive statistics was used in the analysis of the data, and the averages, standard deviation and coefficient of variation calculated for all parameters evaluated. The comparisons between averages were made by non-parametric test. The grazing cattle showed higher levels of globulin and fibrinogen when compared to the confined ones (globulin: $G C=3.29 \mathrm{~g}$ $d L^{-1} \pm 0.76 ; C C=2.99 \mathrm{~g} d L^{-1} \pm 0.60$ and Fibrinogen: $G C=872 \mathrm{mg}$

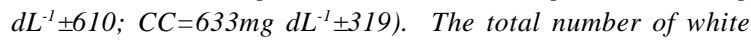
blood cells $m L^{-1}$ was $7.64 \pm 2.15$ in confined cattle and $7.72 \pm 1.84$ in grazing cattle. There was no significant difference between this variable and differential white blood cell count as well as the total serum protein $\left(g d L^{-1}\right)$ from grazing cattle

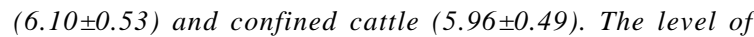
albumin from confined cattle $\left(3.01 \mathrm{~g} \mathrm{dL}^{-1} \pm 0.43\right)$ and the $\mathrm{A} / \mathrm{G}$ ratio (1.07 \pm 8.91$)$ were greater when compared to the grazing bovines $\left(2.82 g d L^{-1} \pm 0.45\right)$ and $(0.95 \pm 0.38)$ respectively. The higher serum levels of albumin found in confined herd suggest that they were subjected to a more adequate nutritional diet. The constant immunological challenge suffered by the GC could be responsible for the elevated serum levels of globulin and fibrinogen. These results showed that although feedlots present a stressful environment they did not show any blood alterations correlated to this fact.

Key words: bovine, feedlot, leukocytes, plasma proteins.

IEscola de Veterinária, Universidade Federal de Goiás (UFG), Av. Perimetral, n 3425, casa 31, St. Coimbra, 74530-020, Goiânia, GO, Brasil. Email: edianeveterinaria@hotmail.com. *Autor para correspondência.

IIInstituto de Patologia Tropical e Saúde Pública, Goiânia, GO, Brasil. 


\section{INTRODUÇÃO}

As avaliações hematológicas nos bovinos são empregadas para analisar doenças em um animal ou para avaliar grupos de animais dentro de um rebanho e ainda para detectar doenças ocultas e direcionar as condutas clínicas (WEISS \& PERMAN, 1992).

A resposta leucocitária em ruminantes freqüentemente difere das observadas em outras espécies (COLE et al., 1997; TAYLOR, 2000). KANTEK \& NAVARRO (2005) atribuem essa diferença ao fato desses animais possuírem um compartimento de reserva leucocitária limitado na medula óssea, fazendo com que os neutrófilos imaturos apareçam rapidamente, nos estados inflamatórios agudos. O leucograma é influenciado por diversos fatores, dentre estes se destacam a idade (TAYLOR, 2000; GONÇALVES et al., 2001; PAULA NETO, 2004), estado gestacional (FAGLIARI et al., 1998; KLINKON \& ZADNIK, 1999; MEGLIAet al., 2005), raça, atividade muscular, excitação (COLE et al., 1997; TAYLOR, 2000) nutrição (ANDRESEN, 1970; OHTSUKA et al., 2005) e estresse do animal (JAIN, 1989; WEISS \& PERMAN, 1992; COLE et al., 1997). Além desses fatores, WILSON et al. (2002) acrescenta que em um sistema de criação de bovinos confinados, a poeira produzida pela movimentação dos bovinos é um problema ambiental, que pode comprometer a saúde dos animais, devido à irritação causada no sistema respiratório. Alem, disso, a “performance” e saúde dos bovinos são fortemente influenciadas pelo clima (MADER, 2003).

Devido à variabilidade da resposta leucocitária às doenças nos bovinos, a avaliação de proteínas como a albumina, a globulina e o fibrinogênio, juntamente ao leucograma, oferece melhor parâmetro de interpretação do que a contagem de leucócitos isoladamente (ECKERSALL \& CONNER, 1988; SUTHERLAND \& WHITNEY, 1995).

Dentre as proteínas plasmáticas, a albumina é a mais abundante. Devido ao grande tamanho da molécula, normalmente ela é retida nos capilares, entretanto, ela é a primeira proteína a ser perdida durante as injúrias teciduais. A hipoalbuminemia é mais bem avaliada em associação com a razão albumina:globulina (A/G), pois um quadro de hipoalbuminemia, combinada com a globulina de normal a aumentada, significa uma razão A/G diminuída. Já a hipoalbuminemia, juntamente com hipoglobulinemia, são traduzidas como uma razão A/G normal (KANEKO, 1989; DUNCAN et al., 1994). Um quadro de hipoalbuminemia auxilia o clínico a limitar o seu diagnóstico diferencial de uma determinada enfermidade(WILLARD, 2000).
Dentre as proteínas de fase aguda, o fibrinogênio e a haptoglobina são indicadores mais sensíveis de inflamações agudas ou crônicas em ruminantes (WEISS \& PERMAN, 1992; VERKKOJULKAISUT, 2000). Isso é possível devido ao aumento da síntese de fibrinogênio pelos hepatócitos, que é resultante do estímulo de Interleucina-1 (IL-1), IL-6 e fator de necrose tumoral, os quais são liberados durante os eventos inflamatórios e/ou traumáticos (JAIN, 1993). Após 24 a 36 horas da injúria tecidual, aumenta a concentração plasmática do fibrinogênio, precedido pelo aumento da gamaglobulina. A concentração do fibrinogênio permanece elevada durante a ação da doença, decrescendo com a melhora do animal, tornando-se assim um bom marcador e avaliador do processo em curso (SUTTON \& HOBMAN, 1975).

A relação proteína plasmática:fibrinogênio (PP:F) é usada para distinguir hiperfibrinogenemia causada por doença ou associada à desidratação. Isso porque a hemoconcentração produz um aumento relativo de todos os componentes das proteínas plasmáticas, incluindo o fibrinogênio (McSHERRY et al., 1970; SUTTON \& HOMAN, 1975; JAIN, 1993). Geralmente, relação PP:F menor que 15:1 indica aumento relativo do fibrinogênio comparado com as proteínas plasmáticas. A relação PP:F abaixo de 10:1 indica aumento absoluto de fibrinogênio (SUTTON \& HOMAN, 1975; BENJAMIN, 1978; JAIN, 1993).

Esse trabalho teve por objetivo avaliar a influência do sistema de criação sobre os valores leucocitários sanguíneos, protéicos séricos e fibrinogênio plasmáticos em bovinos.

\section{MATERIAL E MÉTODOS}

O trabalho foi desenvolvido no Laboratório de Análises Clínicas do Hospital Veterinário da Escola de Veterinária da Universidade Federal de Goiás e na Empresa Frigorífica FRIBOI, localizada no município de Goiânia, Estado de Goiás.

Foram utilizados 120 bovinos, divididos em dois grupos, sendo um grupo composto por 60 animais, oriundos de confinamento e outro grupo de 60 animais, terminados a pasto. Os animais de ambos os grupos eram machos com idades entre 24 a 36 meses, peso médio de $260 \mathrm{~kg}$ e da raça Nelore.

As amostras sanguíneas foram obtidas no corredor de abate, no momento da sangria dos bovinos. Foram coletadas $5 \mathrm{~mL}$ de sangue da jugular em frasco contendo anticoagulante EDTA (ácido etilediaminotetracético, sal dissódico a 10\%, em solução aquosa - Vacutainer, Bcton, Dickinson Ind. Cirúrgicas 
Ltda. Brasil), para a determinação total e diferencial dos leucócitos, além da determinação do fibrinogênio plasmático. Ainda foram coletados $5 \mathrm{~mL}$ de sangue sem anticoagulante, para determinação da proteína total e da albumina sérica. As amostras foram devidamente acondicionadas em caixa de isopor, contendo gelo e transportadas para o LAC/HV, onde foram processadas e analisadas no mesmo dia da colheita.

A contagem de leucócitos foi realizada em câmara de Neubauer, de acordo com as recomendações de JAIN (1993) e MEYER \& HARVEY (2004) e a contagem diferencial de leucócitos foi realizada em esfregaços sanguíneos corados pelo corante Giemsa, conforme JAIN (1993). Para a determinação da proteína sérica total, foi utilizado o método de biureto, utilizandose reagente comercial; da albumina, o verde de bromocresol e a globulina foi determinada pelo resultante da subtração de albumina da proteína total sérica.

O índice albumina:globulina (A:G) foi calculado dividindo-se o valor da fração albumina pelo valor total da fração globulina de cada amostra analisada. O nível de fibrinogênio plasmático foi realizado segundo o método descrito por KANEKO \& SMITH (1964). A determinação da proteína plasmática foi realizada segundo JAIN (1993). A relação PP:F foi obtida diminuindo a concentração de proteína plasmática pela concentração de fibrinogênio, dividido este resultante pela concentração de fibrinogênio (JAIN, 1993).

Foi realizada a estatística descritiva, obtendo-se as médias, desvio padrão e coeficiente de variação para todos os parâmetros avaliados. Após essa análise, aplicou-se o teste não-paramétrico de WILCOXON para a comparação de médias ao nível de significância de 5\% (SAMPAIO, 1998). As análises estatísticas foram realizadas com o programa Sistema de Análises Estatísticas e Genéticas - SAEG (RIBEIRO JÚNIOR, 2001).

\section{RESULTADOS E DISCUSSÃO}

Os valores da contagem total e diferencial de leucócitos e dos constituintes séricos dos bovinos confinados e terminados a pasto estão apresentados na tabela 1. A avaliação da contagem total do número de leucócitos mostrou que não houve diferença significativa entre os bovinos submetidos ao confinamento e os terminados a pasto. Os valores de ambos os grupos encontraram-se abaixo dos valores de referência para a raça, de acordo com estudo feito por COSTA (1994). PAES et al. (2003) estudaram o leucograma de bovinos clinicamente saudáveis, da raça
Nelore, submetidos ao confinamento e obtiveram valor médio para a contagem de leucócitos totais de 10,8 (x $10^{3}$ células $\mathrm{mL}^{-1}$ ), contagens também superiores a deste estudo. Apesar de os bovinos confinados estarem submetidos a muitas situações adversas, tais como aglomerações dos animais que levam a estresse, agressão respiratória por poeira, possibilidade de desenvolver coccidiose pela condição ambiental (DUTRA, 2001), a contagem total de leucócitos desses animais esteve dentro dos padrões normais. A ausência de resposta leucocitária nesses animais, sobretudo nos confinados, pode ser atribuída ao fator racial.

A menor resposta leucocitária nos animais confinados, comparados aos terminados a pasto pode ser atribuída, à elevação do índice dos leucócitos em bovinos nelores a pasto, à constante exposição por carrapatos o que levaria a uma hemoparasitose enzoótica e a uma contínua premunição (BENESI et al., 2002). Na contagem diferencial dos leucócitos, não houve diferença significativa para nenhuma das células analisadas. Os valores aqui encontrados estiveram abaixo da referência estabelecida por COSTA (1994), que atribuiu o destaque linfocitário da contagem à diferencial celular, à ocorrência de hemoparasitoses e/ ou premunição natural e contínua.

Os valores de neutrófilos segmentados encontram-se próximos do observado por COSTA (1994), que foi de 2,95 \pm 457 para bovinos da raça Nelore. Quanto à avaliação do número de neutrófilos, não houve um quadro de neutrofilia que se associasse a um processo inflamatório, já que, segundo MATOS \& MATOS (1988), JAIN (1993) e TAYLOR (2000), os bovinos têm uma resposta leucocitária muito discreta. Valendo ressaltar, entretanto, que o grupo de animais terminados a pasto apresentaram maiores valores das células neutrofílicas, apesar de estatisticamente não ter havido significância.

Os valores médios obtidos para os números absolutos dos eosinófilos $\mu \mathrm{L}^{-1}$ foram de $120 \pm 191$ nos bovinos confinados e de $188 \pm 272$ nos animais terminados a pasto $(\mathrm{P}>0,05)$. Quanto aos monócitos $\mu \mathrm{L}^{-1}$, a quantificação destes não demonstrou diferença entre os grupos.

Na dosagem de proteínas, não houve diferença significativa entre os grupos. Entretanto, foi observada uma hiperproteinemia dos terminados a pasto em relação aos confinados, em razão do maior valor da gamaglobulina nos terminados a pasto. No entanto, os valores médios para proteína total de bovinos confinados, estão abaixo dos achados por DOORNENBAL et al. (1988), que foi de $6,79 \mathrm{~g} \mathrm{dL}^{-1} \mathrm{e}$ BARROS FILHO (1995), que encontrou 6,76 $\pm 0,41$. 
Tabela 1 - Valores do leucograma, da proteína total, da albumina, da globulina, da relação A/G e do fibrinogênio de bovinos terminados em confinamento e a pasto.

\begin{tabular}{llc}
\hline & & \\
Parâmetro & Confinados & Pastejo \\
\hline Leucócitos $\mu \mathrm{L}^{-1}$ & $7.640 \pm 2.150,42 \mathrm{a}$ & $7.725 \pm 1.843,20 \mathrm{a}$ \\
Bastonetes $\mu \mathrm{L}^{-1}$ & $137 \pm 135 \mathrm{a}$ & $126 \pm 159 \mathrm{a}$ \\
Segmentados $\mu \mathrm{L}^{-1}$ & $3.200 \pm 1.095 \mathrm{a}$ & $3.518 \pm 1.278 \mathrm{a}$ \\
Eosinófilos $\mu \mathrm{L}^{-1}$ & $120 \pm 191 \mathrm{a}$ & $188 \pm 272 \mathrm{a}$ \\
Linfócitos $\mu \mathrm{L}^{-1}$ & $3.957 \pm 1.450 \mathrm{a}$ & $3.687 \pm 1.359 \mathrm{a}$ \\
Monócitos $\mu \mathrm{L}^{-1}$ & $207 \pm 168 \mathrm{a}$ & $186 \pm 205 \mathrm{a}$ \\
Proteína total g dL & $6,10 \pm 0,53 \mathrm{a}$ \\
Albumina $\mathrm{dL}^{-1}$ & $5,96 \pm 0,49 \mathrm{a}$ & $2,82 \pm 0,45 \mathrm{~b}$ \\
Globulina g dL & $3,01 \pm 0,43 \mathrm{a}$ & $3,29 \pm 0,76 \mathrm{~b}$ \\
A/G & $2,99 \pm 0,60 \mathrm{a}$ & $0,95 \pm 0,38 \mathrm{~b}$ \\
Fibrinogênio mg dL & $1,07 \pm 0,48 \mathrm{a}$ & $872 \pm 610,39 \mathrm{~b}$ \\
Relação proteína plasmática: fibrinogênio (PP:F) & $633 \pm 319 \mathrm{a}$ & $12,06 \pm 9,40 \mathrm{~b}$ \\
\hline
\end{tabular}

Letras iguais entre linhas indicam ausência de diferença estatística significativa ao nível de significância de 5\%.

O valor encontrado para a concentração sérica de albumina demonstrou diferença significativa entre os dois grupos de animais. $\mathrm{O}$ valor da albumina sérica dos bovinos confinados encontra-se muito próximo do obtido por FAGLIARI et al. (1998) 3,33 $\pm 0,25$ em bovinos machos da raça Nelore, mantidos em pastagem, mas com suplementação mineral. Quanto aos animais terminados a pasto, os valores da albumina foram próximos aos encontrados por GONÇALVES et al. (2001), que foi de 2,92 $\pm 0,3$ para bovinos da raça Guzerá criados a pasto. De acordo com MEYER \& HARVEY (2004), a concentração dessa proteína varia entre as espécies, mas seu valor sérico ou plasmático pode variar entre $2,5 \mathrm{~g} \mathrm{dL}^{-1}$ a $4,5 \mathrm{~g} \mathrm{dL}-1$. Como os bovinos confinados recebem ração balanceada para atender suas necessidades metabólicas e assim favorecer o ganho em peso (CARDOSO, 2000), os níveis mais elevados de albumina nos animais confinados, comparados aos criados a pasto, foi influenciado pelo estado de nutrição, como enfatizado por JAIN (1993) e GARCÉS et al. (2001).

A concentração sérica de globulina em g $\mathrm{dL}^{-1}$ foi mais elevada nos bovinos terminados a pasto, $(\mathrm{P}<0,05)$, se comparada aos bovinos confinados. Esse valor esteve mais próximo dos encontrados por CHORFI et al. (2004), que foi de 2,35 $\mathrm{g} \mathrm{dL}^{-1}$. O valor da concentração de globulina, dos bovinos terminados a pasto, está de acordo com o encontrado por FAGLIARI et al. (1998), que foi de 3,80 $\pm 0,48$ para bovinos Nelore criados também em sistema extensivo. Segundo RAMÍREZ et al. (2001), o aumento da concentração de proteínas plasmáticas é devido à resposta imune do organismo animal aos desafios infecciosos, além do fato de a concentração de globulina nos animais em condições tropicais ser proporcionalmente maior do que a concentração de albumina.

A relação A/G apresentou valores mais elevados nos animais confinados $(\mathrm{P}<0,05)$, comparada a dos animais terminados a pasto. A razão da maior relação do índice A/G foi atribuída ao aumento da concentração de albumina nos animais confinados e maior concentração de globulinas nos terminados a pasto. Segundo observações feitas por BACILA (2003), a relação A/G é importante na avaliação de infecções, quando elas se alteram, invertendo-se os valores pelo incremento que ocorre na concentração das imunoglobulinas, especialmente as $\gamma$-globulinas.

A concentração de fibrinogênio em $\mathrm{mg} \mathrm{dL}^{-1}$, nos bovinos terminados a pasto, foi maior do que os confinados $(\mathrm{P}<0,05)$. Apesar de poucos trabalhos tratarem de fibrinogênio plasmático de zebuínos, os resultados para o fibrinogênio plasmático nesta pesquisa encontraram-se acima dos achados por BARROS FILHO (1995), que foi de $340 \mathrm{mg} \mathrm{dL}^{-1} \mathrm{em}$ Nelores criados extensivamente. A elevação do fibrinogênio plasmático nos animais terminados a pasto pode estar associada aos maiores desafios enfrentados pelos animais, nessas condições, já que o fibrinogênio é uma proteína sinalizadora de fase aguda nos bovinos (JAIN, 1993).

Quanto à relação proteína plasmática/ fibrinogênio, foi encontrado o valor de 12:1 para bovinos terminados a pasto $(\mathrm{P}<0,05)$, sendo, portanto um aumento relativo do fibrinogênio nesse grupo de 
animais, concordando com as afirmações de SUTTON \& HOMAN (1975), BENJAMIN (1978), JAIN (1993) e COLE et al. (1997) que a relação PP:F menor que 15:1 indica um aumento relativo do fibrinogênio. Nos bovinos confinados, a relação PP:F foi de 17:1, estando, portanto, os animais deste grupo em melhores condições orgânicas que os confinados, respaldado na afirmação de COLE et al. (1997), pois, segundo os autores, a relação PP:F maior do que 15:1 é observada em animal normal.

Analisando os resultados do fibrinogênio e do leucograma, percebe-se uma leitura de maior conforto biológico dos animais terminados em confinamentos em relação aos animas terminados a pasto, visto que o fibrinogênio é uma proteína reativa e sinalizadora de fase aguda (JAIN, 1993; COLE et al., 1997) mais sensível que a leitura dos leucócitos (COLE et al., 1997), os quais não tiveram diferença significativa entre os dois grupos estudados, porém mostrando uma reação neutrofílica em números maiores nos bovinos a pasto.

Esses achados foram de encontro a COLE et al. (1997), que afirmaram que a contagem de leucócitos é mais discreta para mostrar uma agressão orgânica nos bovinos, sendo de boa valia somar a esta avaliação a mensuração ao fibrinogênio (McSHERRY et al., 1970; SUTTON \& HOBMAN, 1975; FRASER, 1997).

Neste estudo, entre os fatores que poderiam interferir nas variáveis leucograma e proteínas plasmáticas, destaca-se o fator manejo diferenciado para terminação de bovinos, já que os fatores como a faixa etária, a raça e o sexo não interferiram, pois os animais pertencentes ao estudo estiveram sobre a mesma condição quanto a esses aspectos.

\section{CONCLUSÕES}

Maior reação na leitura do leucograma foi observada nos animais terminados a pasto. A concentração de globulinas e de fibrinogênio foi maior nos animais terminados a pasto. A relação albumina/ globulina foi maior nos animais confinados.

\section{REFERÊNCIAS}

ANDRESEN, H.A. Evaluation of leukopenia in cattle. Journal American Veterinary Medical Association, Schaumburg, v.156, n.7, p.858-867, 1970.

BACILA, M. Bioquímica veterinária. São Paulo: Robe, 2003. 583p.

BARROS FILHO, I.R. Contribuição ao estudo da bioquímica clínica em zebuínos da raça Nelore criados no estado de São Paulo: Influência dos fatores etários e do tipo racial. 1995. 132f. Dissertação (Mestrado em Patologia Clínica Animal) - Curso de Pós-graduação em Clínica Veterinária, Universidade de São Paulo.

BENESI, F.J. et al. Leucograma padrão de bovines da raça Nelore (Bos indicus) influência de fatores sexuais. Veterinária Notícias, Uberlândia, v.8, n.1, p.59-66, 2002.

BENJAMIN, M.M. Interpretation of hematologic findings. In: ______. Outline of veterinary clinical pathology. 3.ed. Ames: Iowa State University, 1978. p.76-107.

CARDOSO, E.G. Confinamento de bovinos, 2000. Capturado em 14 de jun. 2004. Online. Disponível http:// cnpgc.embrapa.br/publicacoes/naoseriadas/cursosuplementacao/ confinamento.

CHORFI, Y. et al. Evaluation of variation n serum globulin concentrations in dairy cattle. Veterinary Clinical Pathology, Davis, v.33, n.3, p.122-127, 2004.

COLE, D.C. et al. Interpreting a bovine CBC: Evaluation the leukon and acute-phase proteins. Veterinary Medicine, London, v.92, n.5, p.470-478, 1997.

COSTA, J.N. Leucograma de zebuínos (Bos indicus, Linnaeus, 1758) sadios da raça Nelore criados no Estado de São Paulo: Influência dos fatores etários e sexuais. 1994. 124f. Dissertação (Mestrado em Patologia Clínica) Curso de Pós-graduação em Clínica Veterinária, Universidade de São Paulo.

DOORNENBAL, H. et al. References values of blood parameters in beef cattle of different ages and stages of lactation. Canadian Journal Veterinary Research, Ottawa, v.52, n.1, p.99-105, 1988.

DUNCAN, J.R. et al. Veterinary laboratory medicine. 3.ed. Ames IA: Iowa State University, 1994. 118p.

DUTRA, I.S. Programa sanitário para confinamentos. In SEMINÁRIO INTERNACIONAL NUTRON SOBRE NUTRIÇÃO DE BOVINOS, 3., 2001, Goiânia: entidade. Anais... Goiânia, 2001. p.3.

ECKERSALL, P.D; CONNER, J.G. Bovine and canine acute phase proteins. Veterinary Research Communication, Netherlands, n.2-3, v.12, p.169-178, 1988.

FAGLIARI, J.J. et al. Constituintes sanguíneos de bovinos lactentes, desmamados e adultos das raças Nelore (Bos indicus) e Holandesa (Bos taurus) e de bubalinos (Bos bubalis) da raça Murrah. Arquivo Brasileiro de Medicina Veterinária e Zootecnia, Belo Horizonte, v.50, n.3, p.263-271, 1998.

FRASER, C.M. Manual Merck de veterinária. 7.ed. São Paulo: ROCA, 1997. 2169p.

GARCÉS, M.L.V. et al. Observaciones hematoquímicas em um rebanho de vacas lecheras com freqüentes estados de anemia. Revista Produccion Animal, Camaguey, v.13, n.1, p.83-88, 2001.

GONÇALVES, R.C. et al. Influência da idade e do sexo sobre o 
hemograma, proteínas séricas totais, albumina e globulina de bovinos sadios da raça Guzerá (Bos indicus). Veterinárias Notícias, Uberlândia, v.7, n.1, p.61-68, 2001.

JAIN N.C et al. Haematological changes in buffalo calves inoculated with Escherichia coli endotoxin and corticosteroids Research Veterinary Science, London, v.47, n.3, p.305308, 1989.

JAIN, N.C. Essentials of veterinary hematology. Philadelphia: Lea \& Febiger, 1993. 417p.

KANEKO, J.J. Clinical biochemistry of domestic animal. 4.ed. San Diego: Academic, 1989. 932p.

KANEKO, J.J.; SMITH, R. The estimation of plasma fibrinogen and its clinical significance in the dog. California Veterinarian, Sacramento, v.21, n.4, p.21-24, 1964.

KANTEK, C.E.; NAVARRO, K.G. Manual de hematologia veterinária. 2.ed. São Paulo: Varela, 2005. 206p.

KLINKON, M.; ZADNIK, T. Dynamics of red and white blood picture in dairy cows during the periparturient period. Comparative Hematology International, London, v.9, n.3, p.156-161, 1999.

MADER, T.L. Environmental stress in confined beef cattle. Journal of Animal Science, Champaign, v.81, s/n , p.110119, 2003.

MATOS, M.S.; MATOS, P.F. Laboratório clínico médico veterinário. São Paulo: Atheneu, 1988. 238p.

McSHERRY, B. et al. Plasma fibrinogen levels in normal and sick cows. Canadian Journal of Comparative Medicine, Ottawa, v.34, n.3, p.191-197, 1970.

MEGLIA, G.E. et al. Effects of feeding intensity during the dry period on leukocyte and lymphocyte sub-populations, neutrophil function and health in periparturient dairy cows. Veterinary Journal, Switzerland, v.169, n.3, p.376-384, 2005.

MEYER, D.J.; HARVEY, J.W. Veterinary laboratory medicine: interpretation \& diagnosis. 2.ed. Philadelphia: Sauders, 2004. 351p.

OHTSUKA, H. et al. Effect of nutritional condictions on changes in leukocyte populations in Japanese black calves. Journal Veterinary Medical Science, Oxford, v.67, n.2, p.183-185, 2005.

PAES, P.R.O. et al. Leucograma de bovinos Nelore, Brangus e mestiços Nelore x Angus com idade entre 10 a 12 meses, submetidos ao mesmo regime de manejo. In: CONGRESSO LATINO AMERICANO, 11.; CONGRESSO BRASILEIRO, 5.; CONGRESSO NORDESTINO DE BUIATRIA, 3., Salvador. Resumos... Salvador: Associação Brasileira de Buiatria, 2003. p.37.

PAULA NETO, J.B. Hemogramas de bovinos (Bos taurus) sadios da raça Curraleiro de diferentes idades, machos e fêmeas, gestantes e não gestantes. 2004. 65f. Dissertação (Mestrado em Sanidade Animal) - Curso de Pósgraduação em Ciência Animal, Universidade Federal de Goiás.

RAMÍREZ, M.N. et al. Relación albumina:globulina plasmáticas en tres épocas Del año en vacas de la raza Carora Del estado Lara-Venezuela. In: CONGRESSO NACIONAL DE BUIATRIA, 2001, Vera Cruz. Anales... Vera Cruz, 2001.

RIBEIRO JÚNIOR. Análises estatísticas no SAEG. Viçosa: UFV, 2001. 301p.

SAMPAIO, I.B.M. Estatística aplicada à experimentação animal. Belo Horizonte: Fundação de Ensino e Pesquisa em Medicina Veterinária e Zootecnia, 1998. 221p.

SUTHERLAND, R.J.; WHITNEY, M.S. Acute phase proteins in bovine inflammatory diseases. Texas Vet, Austin, v.57, n.6, p.27-29, 1995.

SUTTON, R.H.; HOBMAN, B. The value of plasma fibrinogen estimations in cattle: a comparison with total leukocyte and neutrophil counts. New Zealand Veterinary Journal, Palmeston, v.23, n.3, p.21-27, 1975.

TAYLOR, J.A. Leukocyte responses in ruminants. In: FELDMAN, B.F. et al. Schalm's veterinary hematology. 5.ed. Philadelphia: Wilkins, 2000. p.891-898.

VEKKOJULKAISUT, H.Y. Hirvonen's thesis on acute phase response in dairy cattle. 2000. 79f. Thesis - Satu, University of Helsinki, Pyörälä.

WEISS, D.J.; PERMAN, V.P. Assessment of the hematopoietic system in ruminants. Veterinary Clinics of North America: Food Animal Pratice, Philadelphia, v.8, n.2, p.411-429, 1992.

WILLARD, M.D. Hypoalbuminemia. In: FELDMAN, B.F. et al. Schalm's veterinary hematology. 5.ed. Philadelphia: Wilkins, 2000. p.891-898.

WILSON, S.C. et al. Airbone microbial flora in a cattle feedlot. Applied and Environental Microbiology, Washington, v.68, n.7, p.3238-3242, 2002. 